\title{
Energy optimization of chillers by automating a Cooling System
}

\author{
Wilson E. Sánchez ${ }^{1}$, Bryan L. Robayo ${ }^{1}$, Pablo E. Rodríguez ${ }^{1}$, Martha E. Salazar ${ }^{2}$, Santiago Jácome ${ }^{1}$ and Alvaro S. Mullo ${ }^{1}$ \\ ${ }^{1}$ Departamento de Eléctrica y Electrónica, Universidad de las Fuerzas Armadas ESPE, ID: 60104598, Sangolquí, Ecuador \\ ${ }^{2}$ Departamento de Ciencias Exactas, Universidad de las Fuerzas Armadas ESPE, ID: 60104598, Sangolquí, Ecuador
}

\begin{abstract}
This publication presents the work done on energy optimization of a group of chillers by automating the cooling system of blowing dies in an industry that is entrusted with the manufacture of plastic containers. In a first stage, the preliminary study on the energy analysis of the old system, where each chiller was in charge of cooling a specific group of blow moulding machines, without taking into account whether or not the blow moulding machines are working, is detailed; subsequent to this, the implementation of the automated cooling system was carried out, where all chillers were centralized in a machine room, automation was carried out with a Siemens S7-1200 PLC, switching the chillers on and off is based on the total thermal capacity required by the blow moulding machines. Finally, the energy analysis of the new cooling system was carried out, where the results were compared, and conclusions were drawn.
\end{abstract}

\section{Introduction}

Recent reports and perspectives on electricity show a widening gap between electricity generation and electricity demand. Energy costs are therefore a determining factor in economic and social prosperity. As a result, policy, industry and research focus both on the exploitation of alternative energy sources for energy generation and on the development of concepts, methodologies and technologies to reduce energy consumption. An outstanding challenge is energy analysis and optimization of complex systems, such as industrial automation systems. The individuality and dynamics of the system environment during operation make it difficult to identify goal-oriented optimization measures. This contribution proposes a model-based and user-centered approach to automatic energy analysis. This approach helps users to reduce their energy costs through automated generation and implementation of individual proposals for optimizing electrical energy for their industrial automation systems [1].

The availability of conventional energy resources is declining [2]. At the same time, the demand for electrical energy is increasing due to the constant increase in the number of devices and systems that consume electrical energy [3]. These conflicting trends lead to an increase in energy costs affecting all economic and social sectors. The efforts of politics, industry and academia are aimed at both alternatives for power generation and technologies and concepts to reduce the energy consumption of electrical devices and systems. Industrial automation systems are typical devices that consume electrical energy. These must be optimized to help meet the challenges ahead in the energy sector. Industrial automation systems comprise systems that contain a technical process within a technical system. The technical system consists of the communication system, computers, sensors, actors and process operators necessary to automate the technical process [4]. Technical systems are technical products or technical installations. Technical systems that can be characterized as mass products with few sensors and actuators and a high degree of automation are technical products (e. g. a washing machine). Technical plants are unique systems with a high number of sensors and actuators and a medium to high degree of automation. Industrial automation systems are widely used in private homes, workplaces or intersected areas such as public and commercial transport. Users must handle different and complex industrial automation systems. The growing number and increasing complexity of the systems capture much of the attention of users. Additional tasks, such as energy cost analysis, can be easily overloaded [5].

Today, the price of energy is rising. Awareness of the environmental sustainability of governments and customers has been increasing. As a result, manufacturing companies are increasingly motivated to reduce the energy cost of their production activities [6].

Many manufacturing processes require the careful control of surface temperatures, and heat transfer rates, to increase production and improve product quality. Injection moulding, blow moulding, die casting and extrusion are all examples of manufacturing processes that can benefit from incorporating methods of increased and balanced heat transfer within the tooling. For injection moulding, heat transfer is usually carried out using straight cooling channels drilled into the mould. As cooling accounts for a large portion of the total cycle time, this can lead to significant cost savings. Schmidt et al. [7] showed in one case study that $3 \mathrm{D}$ printed conformal cooling tool inserts reduced cooling and cycle 
times by $19-20 \%$ over conventionally machined inserts. Many other manufacturing processes may also benefit from advanced thermal management of the tooling. Shayfull et al. [8] concluded that rapid heat cycle moulding, in which the mould is heated and cooled for each cycle is also likely to benefit greatly from conformal cooling, however this is yet to be fully explored. Au and $\mathrm{Yu}$ carried out computer aided engineering simulations to demonstrate the benefits of conformal cooling over conventional cooling for blow moulding tooling [9]. Hölker et al. showed that conformal cooling of extrusion dies could reduce surface defects on the extruded material [10]. Armillotta et al. showed that conformal cooling improves the surface quality of die cast parts, reduces cycle time and reduces part porosity [11].

Improving the energy efficiency of manufacturing processes is one of the top priorities in the sustainable energy hierarchy and is a widely adopted strategy by industry to reduce energy usage, emissions and costs [12].

\section{Experimental Investigation}

The energy consumption of chillers is associated with the plant's production capacity. The start-up of the blowers generates a thermal load, which must be extracted by the chillers (Table 1). At this time, the blow moulding machines associated with the corresponding chillers worked at their maximum production capacity. The equipment used was the FLUKE 1735 Power Logger.

When a chiller starts up, it scans the system (pressure and coolant level, water level in the storage tank, temperature range setting), and if there are no alarms, it starts the main pump, which circulates the water through the system. Depending on the temperature of the water in the chiller tank, the compressor of the refrigeration circuit will turn on and by means of the coil located inside the chiller tank, cool the process water.

Table 1. Working Temperatures of the mould in operation.

\begin{tabular}{|l|c|}
\hline \multicolumn{1}{|c|}{ Zone } & Temperature [ ${ }^{\circ} \mathbf{C}$ ] \\
\hline Extruded eyelid outer face & 170 \\
\hline $\begin{array}{l}\text { Outer face of extruded } \\
\text { container }\end{array}$ & 60 \\
\hline $\begin{array}{l}\text { Outer side of matrix in } \\
\text { contact with extruded } \\
\text { parison }\end{array}$ & 40 \\
\hline $\begin{array}{l}\text { Water temperature at matrix } \\
\text { inlet }\end{array}$ & 7 \\
\hline
\end{tabular}

\subsection{Analysis of energy consumption chiller HENN M. T. A. TAE 101}

Data collection with the FLUKE 1735 Power Logger analyzer started at $16 \mathrm{~h} 36$ on December 1, 2016 and ended at $14 \mathrm{~h} 00$ on December 2, 2016. In order to analyze in greater detail, the power values demanded by the chiller, a random hour lapse was taken, since, as can be seen in the general graph (figure 1), the power curve demanded is periodic, in addition it is observed that there are two levels of power consumed, one representing the exclusive consumption of the pump, and another higher power level, in which the consumption corresponds to the pump and the refrigeration compressor, working simultaneously.

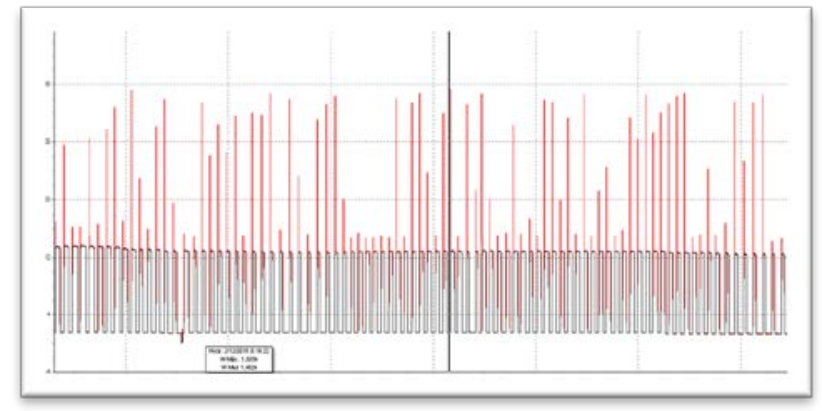

Fig. 1. Wer demanded by chiller HENN.

Figure 2. It is considered a one-hour interval (17:00 to 18:00), in which two different power values are distinguished in different periods of time.

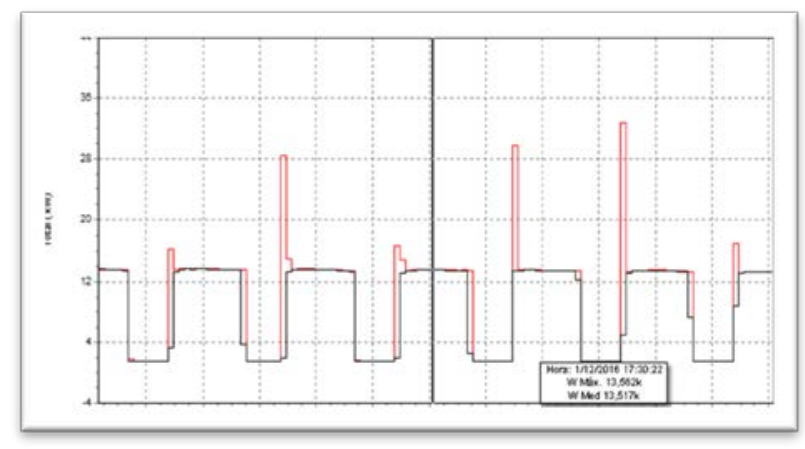

Fig. 2. Power required by the pump and compressor.

The highest value (13.517[kW]) corresponds to the combined power requirement between the main pump and the refrigeration circuit (compressor). It can be observed that the average duration of this power demand value is six minutes. The peak values shown in the graph correspond to the values of the compressor starting current, whose value is $32.84[\mathrm{~kW}]$.

The lowest required power value corresponds to the load of the pump in the hydraulic circuit, whose value is $1.505[\mathrm{~kW}$, with an average duration of 4 minutes. (Figure 3).

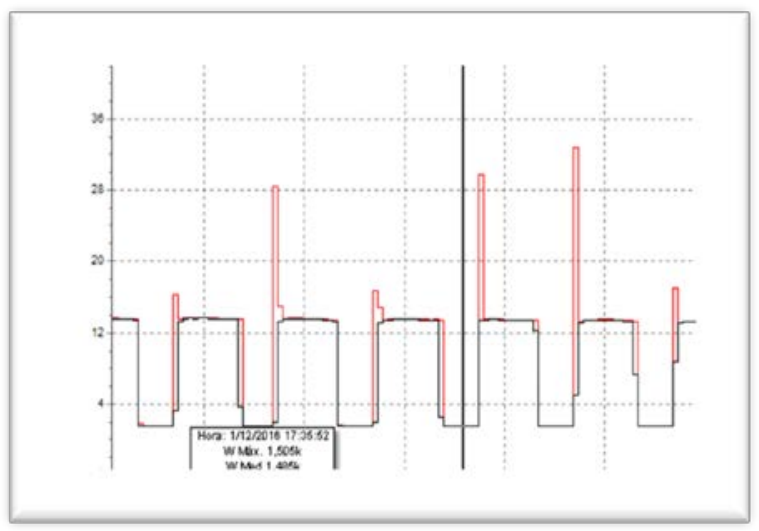

Fig. 3. Power required by the pump. 
Analyzing figure 3, the duration of each cycle is 10 minutes, having six cycles in one hour, of which $60 \%$ of the time $(0.6 \mathrm{~h})$ the compressor and pump are active, while the remaining $40 \%$ only works the pump $(0.4 \mathrm{~h})$. With this data, the estimated energy consumption corresponding to the compressor of the HENN chiller is calculated. ( $\left.\mathrm{E}_{\mathrm{CHENN}}\right)$

$$
\begin{gathered}
E_{C H E N N}=\text { Time } \times \text { Power } \\
E_{\text {CHENN }}=0.6[\mathrm{~h}] \times 13,517[\mathrm{KW}] \\
E_{\text {CHENN }}=8.11[\mathrm{KWh}]
\end{gathered}
$$

Similarly, the power required by the HENN chiller pump is calculated. ( $\left.\mathrm{E}_{\mathrm{BHENN}}\right)$

$$
\begin{gathered}
E_{\text {BHENN }}=\text { Time } \times \text { Power } \\
E_{\text {CHENN }}=0.4[\mathrm{~h}] \times 1,505[\mathrm{KW}] \\
E_{\text {CHENN }}=0.602[\mathrm{KWh}]
\end{gathered}
$$

The total energy consumed of the chiller HENN ( $E_{\text {HENNcalc }}$ ), in one hour will be then:

$$
\begin{gathered}
E_{\text {HENNcalc }}=E_{C H E N N}+E_{\text {BHENN }} \\
E_{\text {HENNcalc }}=8.1[\mathrm{KWh}]+0.6[\mathrm{KWh}] \\
E_{\text {HENNcalc }}=8.713[\mathrm{KWh}]
\end{gathered}
$$

To check the data, a comparison is made with the values obtained in the energy analyzer at the same time interval. (Figure 4)

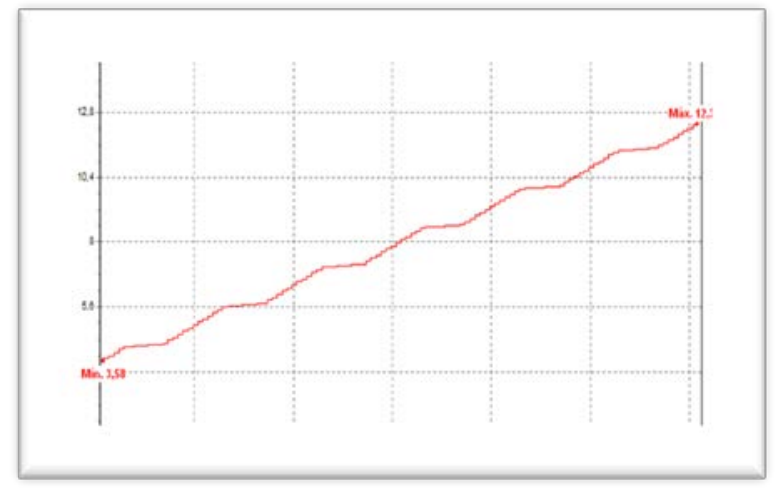

Fig. 4. Energy consumption in one hour of HENN chiller.

$$
\begin{gathered}
E_{\text {HENNdat }}=E_{18 \mathrm{HO0}}-E_{17 \mathrm{HO0}}[\mathrm{kWh}] \\
E_{\text {HENNdat }}=12,324-3,58[\mathrm{kWh}] \\
E_{\text {HENNdat }}=8,74[\mathrm{kWh}]
\end{gathered}
$$

Comparing the calculated energy value ( $\left.E_{\text {HENNcalc }}\right)$ with the energy value obtained by the Power Logger ( $E_{\text {HENNdat }}$ ) of the HENN branded chiller confirms that the calculated values are correct. This energy value is taken as a basis for the calculation of energy consumed monthly by the chiller days.

$$
\begin{gathered}
E_{\text {HENNmes }}=E_{\text {HENNcal }} * 24[\mathrm{~h}] * 30[\text { días }] \\
E_{\text {HENNmes }}=8,713[\mathrm{kWh}] * 24[\mathrm{~h}] * 30[\text { días }] \\
E_{\text {HENNmes }}=6272.78[\mathrm{kWh} / \mathrm{mes}]
\end{gathered}
$$

\subsection{Energy consumption analysis KOOLANT KOOLERS HCV-7500}

Data collection was done with the FLUKE 1735 Power Logger analyzer, started at $15 \mathrm{~h} 12$ on 30 November 2016, and ended at 15 h34 on 1 December 2016.

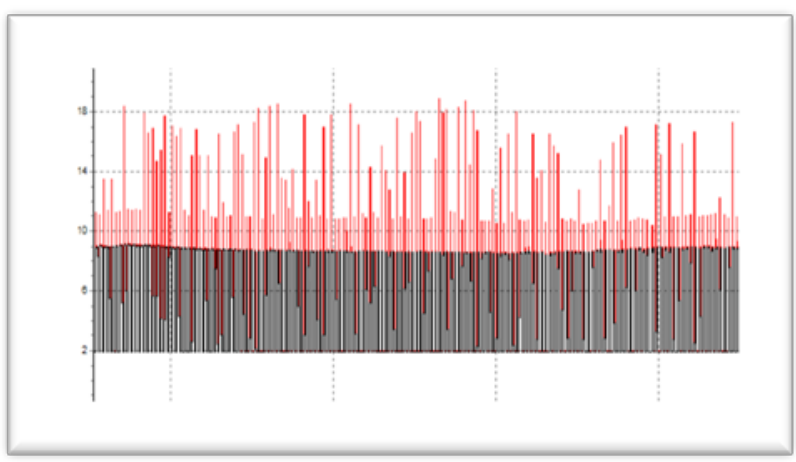

Fig. 5. Power required by the chiller KOOLANT.

To analyze in greater detail, the power values demanded by the chiller, a random hour lapse was taken, since as can be seen in the general graph (figure 5), and the power curve demanded is periodic.

In figure 6, it is considered a one-hour interval (17:00 to 18:00), in which two different power values are distinguished in different periods of time. The power value for the pump starts at 17:26:44 hours (figure 6) and ends at 17:29:44 hours (figure 7), thus determining a time of three minutes, with an average power value of 1.943[kW].

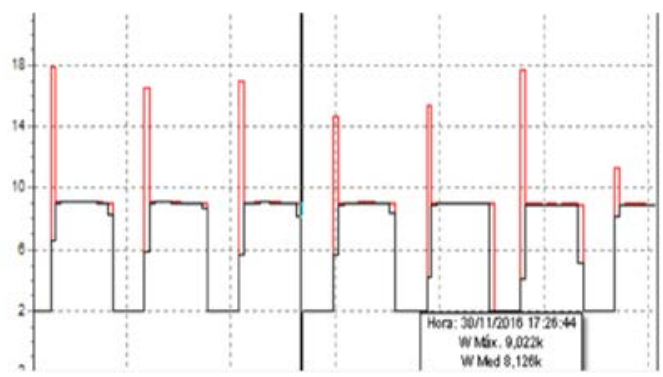

Fig. 6. Start pump working time.

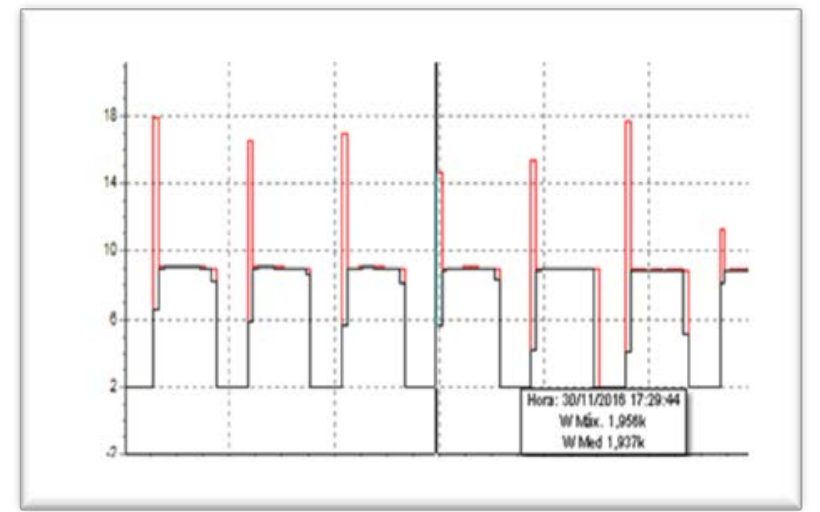

Fig. 7. End of pump runtime. 
The power value for the pump and compressor works at the same time, it starts at 17:29:44 (figure 7) and ends at 17:29:44 (figure 8), thus determining a time period of three minutes, with an average power value of 9.015[kW].

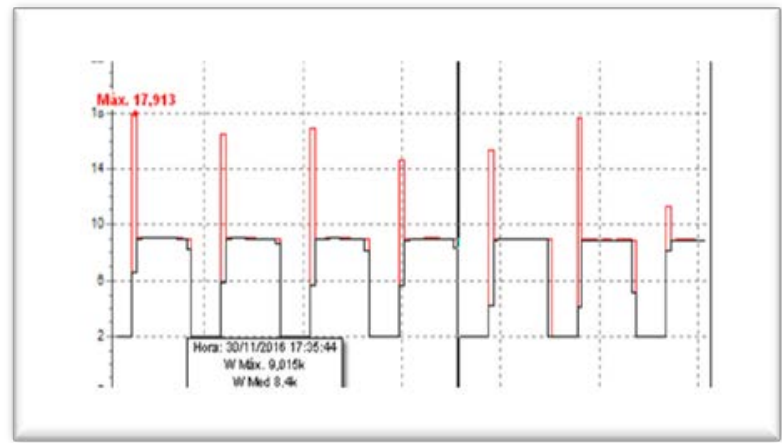

Fig. 8. End of pump and compressor operating time.

Analyzing figure 8, the duration of each cycle is 9 minutes, of which $66.66 \%$ of the time $(0.6666 \mathrm{~h})$ is spent on the compressor and pump, while the remaining 33.33\% only works the pump $(0.3333 \mathrm{~h})$. With this data, the estimated energy consumption corresponding to the compressor and pump of the KOOLANT KOOLERS chiller is calculated.

$$
\begin{gathered}
E_{C K O L}=\text { Tiempo*Potencia } \\
E_{C K O L}=5,417[\mathrm{kWh}]
\end{gathered}
$$

In the same way, we proceed to calculate the power demanded by the chiller KOOLANT KOOLERS pump.

$$
\begin{gathered}
E_{B K O L}=\text { Tiempo*Potencia } \\
E_{B K O L}=0,647[\mathrm{kWh}]
\end{gathered}
$$

The total energy consumed in one hour will then be:

$$
\begin{array}{r}
E_{\text {KOLcal }}=E_{C K O L}+E_{B K O L} \\
E_{\text {KOLcal }}=6,065[\mathrm{kWh}]
\end{array}
$$

To verify the data, a comparison is made with the values obtained in the energy analyzer at the same time interval (Figure 9).

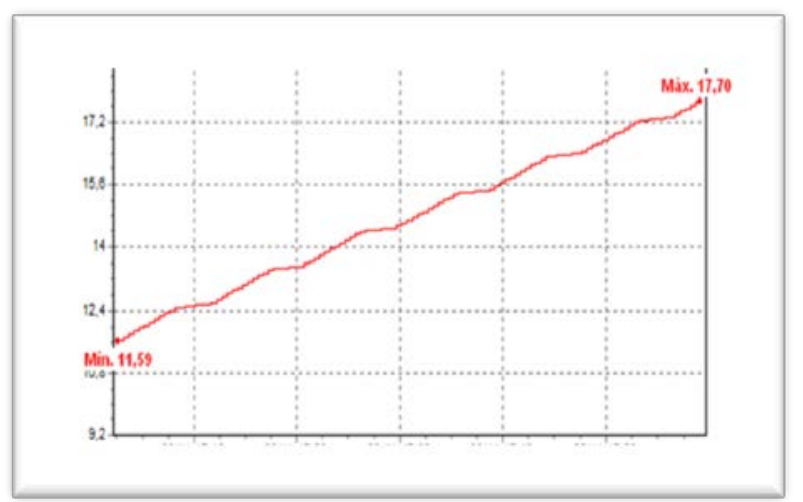

Fig. 9. Energy consumption in one hour of the KOOLANT chiller.

$$
\begin{gathered}
E_{\text {KOLdat }}=E_{18 \mathrm{HOO}}-E_{17 \mathrm{HO0}}[\mathrm{kWh}] \\
E_{\text {KOLdat }}=17,703-11,59[\mathrm{kWh}] \\
E_{\text {KOLdat }}=6,113[\mathrm{kWh}]
\end{gathered}
$$

Comparing the value of the calculated energy $\left(\mathrm{E}_{\mathrm{KOLcal}}\right)$ with the energy value obtained by the Power Logger $\left(E_{K O L d a t}\right)$ confirms that the calculated values are correct. This energy value is taken as the basis for the calculation of the energy consumed monthly by the KOOLANT KOOLERS chiller.

$$
\begin{gathered}
E_{\text {KOLmes }}=E_{\text {KOLcal }} * 24[\mathrm{~h}] * 30 \text { [días] } \\
E_{\text {KOLmes }}=4366,08[\mathrm{kWh} / \mathrm{mes}]
\end{gathered}
$$

\subsection{Analysis of cooling system costs}

The monthly energy consumption corresponding to the load of the current cooling system of the production matrices, and the costs associated with this process, depend on the equipment used to accomplish this task. The monthly energy consumption is then projected.

$$
\begin{array}{r}
E_{\text {SEmes }}=E_{\text {HENNmes }}+E_{\text {KOLmes }}+E_{\text {O3mes }} \\
E_{\text {SEmes }}=14929,34[\mathrm{kWh} / \mathrm{mes}]
\end{array}
$$

\subsection{Analysis of energy consumption already implemented the new cooling system}

The energy readings corresponding to the cooling equipment were carried out in three connection configurations. These readings were performed with the AEMC 3945 power analyzer. (Figure 10)

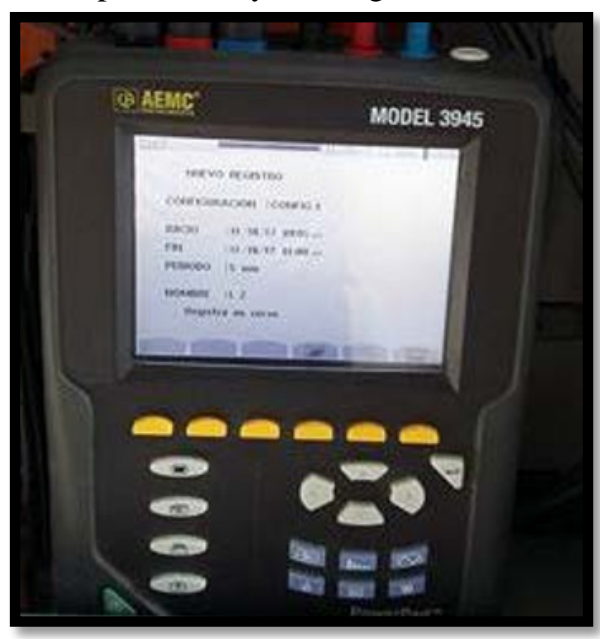

Fig. 10. Energy Analyzer AEMC 3945.

The reading corresponding to the energy consumption of chiller 01 (TAE EVO 201), started at $18: 20$ on $15 / 11 / 2017$ and ended at $08: 30$ on $16 / 11 / 2017$. (Figure 11) 


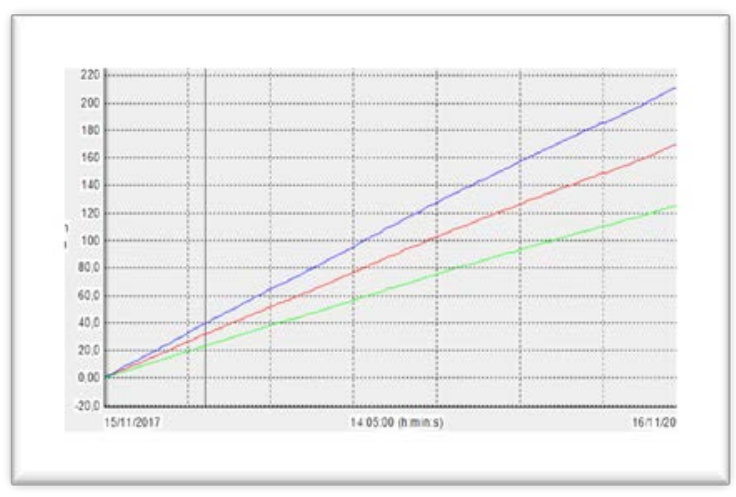

Fig. 11. Energy consumption curve chiller TAE EVO 201.

As a result, an average consumption value of 12.45[kWh] was obtained, and by performing an energy consumption analysis with the same considerations as the analysis of energy consumption prior to redesign, it is obtained:

$$
\begin{gathered}
E_{01}=12,45[\mathrm{kWh}] \\
E_{01 \mathrm{mes}}=12,45 * 24[\mathrm{~h}] * 30 \text { [días] } \\
E_{01 \mathrm{mes}}=8964[\mathrm{kWh} / \mathrm{mes}]
\end{gathered}
$$

The reading corresponding to the energy consumption of chiller 02 (TAE EVO 161), started at 09:05 on 16/11/2017 and ended at 12:55 on 16/11/2017. (Figure 12)

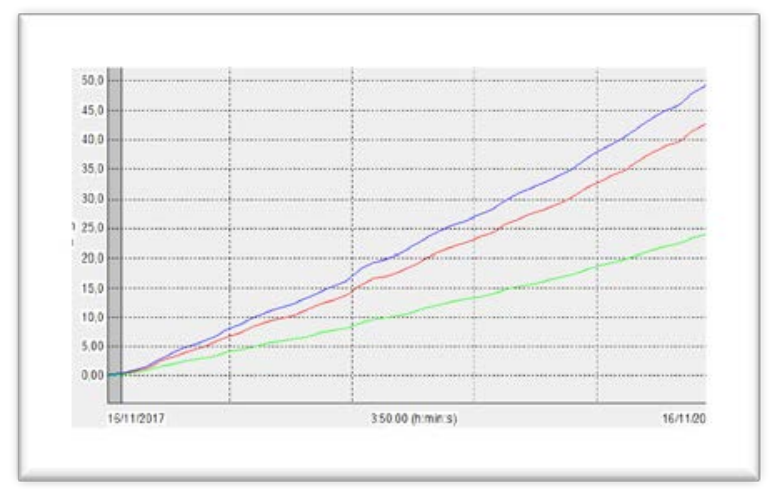

Fig. 12. Energy consumption curve chiller TAE EVO 161.

As a result, an average consumption value of 10.89 [kWh] was obtained, and by performing an energy consumption analysis with the same considerations as the analysis of energy consumption prior to redesign, it is obtained:

$$
\begin{gathered}
E_{02 \mathrm{mes}}=10,89 * 24[\mathrm{~h}] * 30[\text { días }] \\
E_{02 \mathrm{mes}}=7846.2[\mathrm{kWh} / \mathrm{mes}]
\end{gathered}
$$

Chiller 01 and chiller 02 configuration on: the reading corresponding to the energy consumption of chillers 01 and 02 , started at 13:05 on 16/11/2017 and ended at 15:05 on 16/11/2017. (Figure 13)

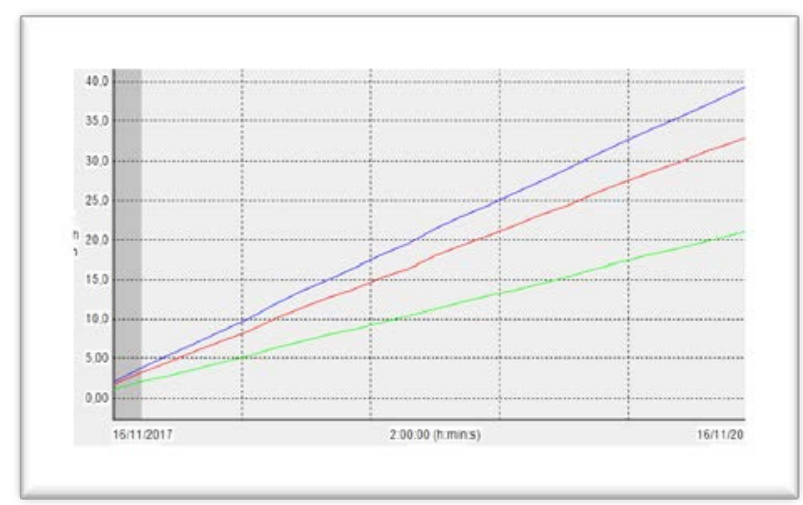

Fig. 13. Energy consumption curve chiller 01 and chiller 02 .

As a result, an average consumption value of 16,775 [kWh] was obtained, and by carrying out an energy consumption analysis with the same considerations as the analysis of energy consumption prior to the redesign, it is obtained:

$$
\begin{gathered}
E_{01 y 02}=16,775[\mathrm{kWh}] \\
E_{\text {01y02mes }}=16,775 * 24[\mathrm{~h}] * 30 \text { [días] } \\
E_{\text {01y02mes }}=12078[\mathrm{kWh} / \mathrm{mes}]
\end{gathered}
$$

\subsection{Validation of the hypothesis}

To validate the hypothesis, it is necessary to compare the results obtained in the previous analysis of energy consumption and the results obtained in the analysis after implementing the new cooling system, for this purpose the following operation is carried out:

Ahorro $=(1-(12078[\mathrm{kWh} / \mathrm{mes}]) /(14929,34[\mathrm{kWh} / \mathrm{mes}])) \times 100 \%$
Ahorro $=19,09 \%$

As we can see, there is an average saving of $19 \%$ which means that the reduction in energy consumption is significant.

\section{Contribution of the study to the field}

The implementation and study of the automation of a chillers cooling system by means of simulations with the computational fluid dynamics tool, makes it possible to study cases for new refrigerant liquids, as well as to determine better finishes for systems or products that use chillers as part of the cooling system. Industrial automation undoubtedly helps industrial processes to be optimized both in production costs and energy efficiency, with the automation of the cooling system achieved a considerable reduction in energy and thus contributing to the saving of energy resources.

This publication contributes to the further implementation of industrial process automation as it optimizes both environmental and energy resources

\section{Conclusions}

With the implementation of the new automatic cooling system for the dies of plastic blow moulding machines, a 
saving of $19 \%$ in the energy consumption of the chillers was achieved.

From the location of the chillers in a centralized machine room, it allowed to reduce the ambient temperature in the production area to an average of $20^{\circ} \mathrm{C}$, and thus the workers develop their activities in a cooler and more suitable climate.

By recording the time of the plastic blow moulding machines, the optimization of the production times was achieved, thus achieving a reduction in the production cost of plastic containers

\section{References}

1. Becka y P. Gohneraa, Models for Model-BAsed User-Centric Energy Analysis of Industrial Automation Systems, ELSEVIER, vol. 6, pp. 423428, (2011).

2. OECD/IEA, World Energy Outllok 2009. Executive Summary, 15 Mai (2011). [En línea]. Available: http://www.iea.org/Textbase/npsum/weo2009sum.p df.

3. L. A. Barroso y U. Holzle, The Case for EnergyProportional Computing, IEE Transactions on Computers, vol. 40, $\mathrm{n}^{\circ}$ 12, pp. 33-37, December (2007).

4. P. Gohner, What is Industrial Automation?, $15 \mathrm{MAi}$ (2011). [En línea]. Available: http://www.ias.unistuttgart.de/ia/unterlagen/umdruck/chapter01.pdf.

5. H. Vieritz, F. Yazdi, N. Jazdi, D. Schilberg, S. Jeschke y P. Goehner, Discussions on accessibility in industrial automation systems, IEEE
International Symposium on Applied Machine Intelligence and Informatics, (2011).

6. X. Gong, T. De Pessemier, W. Joseph y L. Martens, A power data driven energy-cost-aware production scheduling method for sustainable manufacturing, IEEE International Conference on Emerging Technologies and Factory Automation, ETFA, vol. 2016, n ${ }^{\circ}$ 7733716, (2016).

7. S. WR, W. RD, B. CE y B. JV, Conforman Cooling Versus Conventional Cooling: An Injection Molding CAse Study With P-20 anda 3DPTM-Processed Tooling, MRS Proc, vol. 625, p. 51, (2000).

8. S. Z, S. S, Z. AM, G. MF y S. RM, Potential of Conformal Cooling Channels in Rapid Heat Cycle Molding: A Review, Adv Plym Technol, p. 33, (2014).

9. A. KM y Y. Km, Conformal cooling channel design and CAE simulation for rapid blow mould, Int J Adv Manuf Technol, vol. 66, pp. 11-24, (2013).

10. R. Holker, A. Jager, B. Khalifa y A. Tekkaya, Controlling heat balance in hot aluminium extrusion by additive manufactured extrusion dies with conformal cooling channels, Int J Precis Eng Manuf, vol. 14, no 1487, p. 93, (2013).

11. A. Armillotta, R. Baraggi y F. S, SLM tooling for die casting with conformal cooling channels, Int Adv Manuf Technol, vol. 71, n 573, p. 83, (2014).

12. W. Bader y J. Kissock, Exergy Analysis of Industrial Air Compression, National Industrail Energy Technology Conference, vol. 22, (2000). 